\title{
“CHECAR \\ FATOS E \\ DESMENTIR \\ BOATOS": \\ FAKE NEWS \\ E DISCURSO \\ JORNALÍSTICO \\ NO BRASIL
}

\section{“VERIFICAR HECHOS Y REFUTAR RUMORES”: NOTICIAS FALSAS Y DISCURSO PERIODÍSTICO EN BRASIL}

\author{
“CHECK FACTS AND DISPROVING RUMORS”: FAKE NEWS AND JOURNALISTIC DISCOURSE \\ IN BRAZIL
}

Silmara Dela Silva*

Universidade Federal Fluminense

RESUMO: Neste trabalho, voltamo-nos ao funcionamento do discurso sobre o jornalismo e a sua prática no Brasil, dirigindo nossa atenção aos serviços de checagem de fatos (fact checking), que passaram a ganhar espaço e circular mais intensamente na grande mídia no ano de 2018. Da perspectiva teórico-metodológica da análise de discurso, que toma como objeto o discurso enquanto efeito de sentidos que decorrem da inscrição da língua na história, constituímos nosso corpus de análise tomando como foco os blogs: Estadão Verifica, lançado em junho de 2018, pelo jornal O Estado de S. Paulo; e É isso mesmo?, posto em funcionamento em março de 2017, pelo grupo O Globo. Diante de dizeres sobre esses serviços de checagem, bem como dos discursos em circulação em suas páginas digitais, propomos uma reflexão teórico-analítica acerca do fazer jornalístico e a construção de acontecimentos no atual contexto sócio-histórico brasileiro.

PALAVRAS-CHAVE: Análise de discurso. Discurso jornalístico. Agências de checagem. Fake news.

RESUMEN: En este trabajo, nos referimos al funcionamiento del discurso sobre periodismo y su práctica en Brasil, dirigiendo nuestra atención a los servicios de verificación de hechos, que comenzaron a ganar espacio y a circular más intensamente en los

*Professora Associada do Departamento de Ciências da Linguagem da Universidade Federal Fluminense (UFF). Jovem Cientistado Nosso EstadoFAPERJ(2018-2022). É jornalista edoutora em Linguística. E-mail: silmaradela@gmail.com. 
principales medios en 2018. Desde la perspectiva teórico-metodológica del análisis del discurso, que toma el discurso como un efecto de los sentidos que resultan de la inscripción del lenguaje en la historia, formamos nuestro corpus de análisis, centrándonos en los blogs: Estadão Verifica, lanzado en junio de 2018, por el periódico O Estado de S. Paulo; y É isso mesmo? ("¿Es eso correcto?"), lanzado en marzo de 2017, por el grupo O Globo. Ante las declaraciones sobre estos servicios de verificación, así como los discursos en circulación en sus páginas digitales, proponemos una reflexión teórico-analítica sobre la práctica periodística y la construcción de eventos en el contexto socio-histórico brasileño actual.

PALABRAS CLAVE: Análisis del discurso. Discurso periodístico. Agencias de cheques. Noticias falsas.

ABSTRACT: In this paper, we turn to the functioning of the discourse on journalism and its practice in Brazil, directing our attention to fact checking services, which started to gain space and circulate more intensely in the mainstream media in 2018. From the theoretical-methodological perspective of discourse analysis, which takes discourse as an effect of meanings resulting from the inscription of language in history, we constituted our corpus of analysis, focusing on blogs: Estadão Verifica ("Estadão verifies"), launched in June 2018, by the newspaper O Estado de S. Paulo; and É isso mesmo? ("Is that right?"), launched in March 2017, by the O Globo group. Faced with statements about these checking services, as well as the discourses in circulation on their digital pages, we propose a theoretical-analytical reflection on journalistic practice and the construction of events in the current Brazilian sociohistorical context.

KEYWORDS: Discourse analysis. Journalistic discourse. Fact checking. Fake news.

\section{INTRODUÇÃO}

Do médium em transe que se tornou visível pela sua voz na Alemanha radiofônica de 1933, até os fantasmas audiovisuais das mídias contemporâneas, que progressos na arte de fazer marchar as massas, produzindo-lhes o invisivel!

M. Pêcheux (1990 [1982], p. 19)

Na esteira de nossas investigações acerca dos discursos da/na mídia ${ }^{1}$, neste trabalho, voltamo-nos ao funcionamento do discurso sobre o jornalismo e a sua prática no Brasil, dirigindo nossa atenção aos serviços de checagem de fatos (fact checking), que passaram a ganhar espaço e circular mais intensamente na grande mídia brasileira, nos últimos três anos.

Localizamos a reflexão teórico-analítica que propomos na perspectiva teórico-metodológica da análise de discurso instituída por Michel Pêcheux, que toma como objeto o discurso enquanto efeito de sentidos que decorrem da inscrição da língua na história (PÊCHEUX, 1997 [1969], 1997a [1975], 2008 [1983]). No percurso que empreendemos, buscamos analisar: 1) os modos como, no discurso sobre a prática jornalística, constituem-se esses espaços para a checagem de fatos; 2 ) o modo como se constroem efeitos de sentidos para o "fato" e o "boato" nesses novos espaços editoriais; 3 ) as implicações para o discurso jornalístico dessas (novas?) práticas instauradas em nossa conjuntura sócio-histórica.

Para tanto, constituímos nosso corpus de análise tomando como foco os blogs: Estadão Verifica, lançado em junho de 2018 pelo jornal O Estado de S. Paulo, e É isso mesmo?, posto em funcionamento em março de 2017 pelo grupo O Globo. Nosso corpus se volta, assim, a refletir analiticamente a respeito dos serviços de checagem de fatos no modo como foram encampados pela imprensa tradicional em suas práticas, no Brasil, em nossos dias.

Diante dos discursos sobre esses serviços de checagem, bem como de dizeres em circulação em suas páginas digitais, propomos uma reflexão acerca do fazer jornalístico e a construção de acontecimentos no atual contexto sócio-histórico brasileiro. À luz da citação de Pêcheux (1990 [1982]) que mobilizamos como epígrafe, entendemos que o discurso sobre os serviços de checagem de fatos no

${ }^{1}$ As reflexões aqui propostas decorrem da pesquisa $O$ discurso midiático e seu funcionamento: entre o publicitário e o jornalístico, em desenvolvimento no Instituto de Letras da UFF desde outubro de 2018, contemplada no Edital FAPERJ Jovem Cientista do Nosso Estado (2018-2021). 
fazer jornalístico diz dessa produção de um “invisível” pela mídia, que sustenta sua prática de construção dos acontecimentos jornalísticos.

\section{DOS SERVIÇOS DE CHECAGEM DE FATOS NO JORNALISMO BRASILEIRO: A CONSTITUIÇÃO DE UM DISCURSO}

Os serviços de checagem de fatos (fact checking) que elegemos para constituição de nosso corpus de análise ganharam espaço no jornalismo brasileiro nos últimos anos; em especial, voltamo-nos aos anos de 2017 e 2018, quando surgem, respectivamente, os $b l o g s$ Estadão Verifica, lançado pelo jornal O Estado de S. Paulo; e É isso mesmo?, posto em funcionamento pelo grupo O Globo.

O percurso desses serviços na mídia brasileira, no entanto, aponta para o ano de 2015, quando é fundada a Agência Lupa, que se autointitula a "primeira agência de notícias do Brasil a se especializar na técnica jornalística mundialmente conhecida como factchecking" (LUPA, 2015). Em sua página na internet, hospedada no Portal de Notícias UOL, vinculado ao jornal Folha de S. Paulo, a equipe da agência afirma que seu trabalho, efetivamente iniciado em $1^{\circ}$ de novembro de 2015 , teria como objetivo acompanhar "o noticiário de política, economia, cidade, cultura, educação, saúde e relações internacionais, buscando corrigir informações imprecisas e divulgar dados corretos." (LUPA, 2015). Informa, ainda, que as checagens que são por ela realizadas se destinam à comercialização para outros veículos de mídia e à disponibilização em seu próprio site.

Ao dizer de seu trabalho e da agência em si, observamos que a equipe da Agência Lupa constitui efeitos de sentidos para o que é o serviço de checagem de fatos que está implementando/realizando, bem como para o seu alcance e a sua relevância. Com Pêcheux ([1969] 1997), temos que todo processo discursivo se constitui a partir de uma série de projeções que demarcam no discurso as posições ocupadas pelos sujeitos e a representação imaginária do referente sobre o qual incide seu dizer. Em seus termos: “[...] o que funciona nos processos discursivos é uma série de formações imaginárias que designam o lugar que A e B se atribuem cada um a si e ao outro, a imagem que eles se fazem de seu próprio lugar e do lugar do outro." (PÊCHEUX, 1997 [1969], p. 82, itálicos do autor). Em seu dizer, a equipe da Lupa projeta para a agência um imaginário de ineditismo na prática jornalística no Brasil, ao afirmar-se como especialista na "técnica jornalística mundialmente conhecida como fact-checking". Retorna, assim, no fio do discurso, um jádito sobre a prática jornalística como um conjunto de técnicas, sob domínio do profissional do jornalismo, capaz de assegurar a produção de notícias dos variados campos do saber, com base em "dados corretos" e "informações precisas" e, por isso, passíveis de serem comercializadas e publicizadas.

Ao dizer de si mesma como uma agência voltada a "corrigir informações imprecisas e divulgar dados corretos", no entanto, a Lupa também produz sentidos para o jornalismo então praticado no Brasil naquele momento de sua fundação: uma prática que se infere nem sempre ser pautada por "informações precisas" ou pela divulgação de "dados corretos". Isso porque, conforme afirma Orlandi (2001, p. 82), “[... ao longo do dizer, há toda uma margem de não-ditos que também significam”. Diferentemente daquele jornalismo em prática no país, a agência produz para si mesma um imaginário daquela que dispõe de técnicas capazes de chegar às informações precisas e corretas, o que se marca já em seu nome - Lupa - que remete ao objeto que dá a ver de forma ampliada; ou que dá a ver a verdade após uma investigação criteriosa, se tomarmos a lupa, em nosso contexto sócio-histórico, como um objeto tradicionalmente associado à prática do detetive.

Em artigo acerca do funcionamento dos serviços de checagem de notícias no Observatório da Imprensa, assim afirma Caleiro (2020): "As agências de checagem de fatos, dados e declarações (fact-checking) surgiram como uma necessidade determinada pela difusão diária e massiva de notícias mentirosas (fake news), fenômeno que, no bojo da disseminação das redes sociais digitais, tornou-se endêmico a partir de meados da década”. Temos, desse modo, que a necessidade dos serviços de checagem se assenta nas mudanças nas condições de circulação de informações que, com o crescimento das redes sociais digitais - tais como o Facebook, o Twitter e o Whatsapp, por exemplo - entram em concorrência com a mídia jornalística na prática de dar a saber sobre os acontecimentos de um dado período.

Tal como o próprio jornalismo, no modo como se constituiu no país, as agências de checagem de notícias ganharam forma seguindo o modelo de sua implantação nos Estados Unidos. No próprio site da Agência Lupa, ao explicar "de onde vem o fact-checking", são 
retomados aqueles que seriam os momentos inaugurais dessa prática no cenário norte-americano. O trabalho investigativo do jornalista norte-americano Brooks Jackson, encomendado pela CNN em Washington, ainda em 1991, quando das primárias das eleições presidenciais nos Estados Unidos, naquele ano; a fundação do primeiro site independente de fact-checking o FactCheck.org - fundado pelo mesmo jornalista, em 2003, com o apoio da Universidade da Pensilvânia; e a conquista do Prêmio Pulitzer pelo jornalista Bill Adair, do "Tampa Bay Times”, graças à criação de uma seção de checagem em seu jornal, a Politifact.com, naquele mesmo ano, estariam na base dessa "expansão das Plataformas de Checagem" (LUPA, 2015).

Essa expansão é atestada, por exemplo, pela existência de uma associação internacional de verificadores de dados, a International Fact Checking Network (IFCN), vinculada ao Poynter Institute, que possui atualmente 92 agências de checagem como signatárias de seu código de princípios. ${ }^{2}$ Um dos blogs que tomamos para a constituição de nosso corpus de análise, o Estadão Verifica, é um dos signatários da IFCN, assim como a Agência Lupa. O código de princípios a ser seguido pelas agências signatárias para obter a certificação pela IFCN inclui cinco princípios, a saber: i) apartidarismo e imparcialidade; ii) transparência das fontes; iii) transparência do financiamento e da organização; iv) transparência da metodologia; v) e política de correções aberta e honesta (MONNERAT, 2019).

"Apartidarismo", "imparcialidade" e "transparência" são termos muito frequentes no discurso do e sobre o jornalismo e suas práticas. São termos que concorrem para a sustentação da formação imaginária da grande mídia jornalística como isenta e objetiva, imaginariamente capaz de produzir relatos igualmente objetivos sobre os acontecimentos que elege como notícias. Esse imaginário de objetividade e imparcialidade, embora posto em suspenso no interior das próprias teorias do jornalismo, como atestam os trabalhos de Moretzon (2002) e Pena (2015), por exemplo, ainda encontra seu lugar nos manuais de redação e nos princípios editoriais que sustentam as práticas das empresas jornalísticas brasileiras em nossos dias. No Manual de Redação e Estilo do jornal O Estado de S. Paulo, na seção inicial, dedicada a "Instruções gerais", a recomendação está registrada: "Faça textos imparciais e objetivos. Não exponha opiniões, mas fatos, para que o leitor tire deles as próprias conclusões.” (MARTINS, 1997, p. 17). Nos Princípios Editorais das Organizações Globo, por sua vez, tem-se que: "O Grupo Globo será sempre independente, apartidário, laico e praticará um jornalismo que busque a isenção, a correção e a agilidade [...]” (GRUPO GLOBO, s.d.).

Esse imaginário de imparcialidade, isenção e objetividade jornalísticos, que se funda na também imaginária separação entre opinião e informação na prática de produção das notícias, constitui-se discursivamente para os jornais por decorrência de consolidação da imprensa como mídia de massa. Nos termos de Pena (2015, p. 41): “Até o começo do século XX, os jornais eram essencialmente opinativos. [...] As reportagens não escondiam a carga panfletária, defendendo explicitamente as posições dos jornais (e de seus donos) sobre os mais variados temas." A separação entre os espaços para opinião e informação se dá em função da adoção de novas práticas de produção das notícias em grande escala, instituindo os espaços que hoje reconhecemos por opinativos, em oposição às notícias, que passam a seguir técnicas voltadas ao relato impessoal, tomado como objetivo e isento. "É a partir da delimitação desses espaços como opinativos que se produz o efeito de evidência de que os demais espaços existentes em uma publicação não exprimem opiniões, sendo, pois, tão somente informativos." (DELA-SILVA, 2013, p. 1216).

Mariani (1998, p. 63) já discorria a respeito desse funcionamento do discurso jornalístico. Em seus termos: "cabe ao discurso jornalístico organizar e ordenar cotidianamente os acontecimentos, de modo a mostrar que pode haver mais de uma opinião/explicação para o fato em questão, mas nunca um fato diferente do que foi relatado". Em nossas reflexões, temos sustentado que o suposto fato, que ganha circulação na mídia jornalística, advém de uma construção discursiva do próprio jornalismo em suas práticas, resultando no que entendemos como acontecimento jornalístico. Conforme Dela Silva (2015, p. 222), o acontecimento jornalístico "[...] consiste em uma construção do jornalismo, enquanto uma prática discursiva da/na mídia”, uma vez que “[...] o relato jornalístico não se constitui por uma evidência em função de um fato, mas como resultado de um gesto interpretativo a partir de uma determinada posição ideológica” (PÊCHEUX, 1997a [1975]).

Sabemos, com Pêcheux (1997 [1969], p. 77), que todo discurso remete a sentidos outros, o que o permite afirmar que "[...] o processo discursivo não tem, de direito, início: o discurso se conjuga sempre sobre um discursivo prévio”, sobre um já-dito que sustenta a

${ }^{2}$ Considerando número de signatários ativos e em processo de renovação, conforme registros no site da IFCN, em 8 de março de 2020. 
possibilidade mesma dos sentidos. No caso do discurso sobre os serviços de checagem de fatos no jornalismo brasileiro, temos que ele se sustenta por uma memória discursiva que associa a prática jornalística ao relato de um fato a ser atestado, verificado.

\section{ENTRE O “FATO” E O “BOATO”: FACT CHECKING, NOTÍCIAS E FAKE NEWS}

Após discorrermos acerca das condições de produção do discurso sobre os serviços de checagem de fatos, voltando-nos, como propõe Pêcheux ([1969] 1997), a pensar o contexto sócio-histórico que oferece condições para instauração desses discursos e, por consequência, a implementação desses espaços editorais no jornalismo brasileiro, passamos a algumas análises a respeito do funcionamento dos discursos desses serviços de checagem. Para isso, constituímos um corpus de dizeres em curso nos blogs Estadão Verifica e É isso mesmo?, respectivamente associados aos jornais O Estado de S. Paulo e O Globo.

A escolha por esses blogs resulta de nosso interesse em pensar o modo como os serviços de checagem de fatos se constituem, no Brasil, por associação à grande mídia jornalística. Conforme afirmamos em trabalho anterior: "Por grande mídia entendemos a mídia que possui condições privilegiadas de circulação e, consequentemente, ampla representatividade em nossa formação social, por decorrência de seu poderio político-econômico." (DELA-SILVA, 2018, p. 276). Além disso, em termos de circunstâncias imediatas de enunciação, também parte das condições de produção dos discursos (ORLANDI, 2001), os dois serviços de checagem se constituem em um período de tempo próximo, entre março de 2017 e junho de 2018, permitindo-nos, assim, observar as regularidades na produção de discursos acerca da prática de checagem de fatos vinculada a mídias jornalísticas bastante tradicionais no país, a saber Estadão e $O$ Globo.

Em análise de discursividades em torno de "pós-verdade" e "fake news" na materialidade digital, Adorno e Silveira (2019, p. 201, itálicos do original) apontam o modo como tais “[...] denominações fazem trabalhar os sentidos de verdade e mentira, real e ficção, atual e virtual" na rede eletrônica, ao mesmo tempo em que, em seus termos, "no cenário atual, se reorganizam as práticas sociais em torno da produção, divulgação e distribuição de notícias e informações." É justamente confrontando sentidos entre "notícias checadas" e "informações falsas", entre "fatos" e "boatos" que se constituem os blogs com serviços de checagem de informações sobre os quais passamos a nos deter.

Iniciamos nosso gesto de análise detendo-nos sobre quatro sequências discursivas (SD), extraídas da notícia (MONNERAT, 2018) que anuncia o início dos serviços de checagem do Estadão Verifica.

\section{SD1: Recebeu algum boato pelo WhatsApp? Envie para o Estadão Verifica}

Textos, áudios, fotos e vídeos enviados para o número (11) 99263-7900 serão checados

SD2: Você já recebeu textos, áudios, fotos ou vídeos suspeitos no WhatsApp? Por sua facilidade de uso e quase onipresença nos celulares dos brasileiros, o aplicativo é uma ferramenta muito usada na proliferação de notícias falsas. É por isso que o Estadão Verifica criou um canal para receber rumores dos leitores e checar os que estiverem circulando com mais frequência.

SD3: A iniciativa faz parte do monitoramento de redes sociais que será feito por uma equipe de jornalistas do Estado, a fim de combater a desinformação neste ano eleitoral e também depois disso. Nos próximos meses, vamos checar fatos e desmentir boatos, além de produzir matérias sobre o fenômeno das fake news.

SD4: Como o volume de mentiras espalhadas nas redes é grande, não podemos garantir que será possível conferir a veracidade de tudo o que nos for enviado.

Uma primeira observação diz respeito às condições imediatas de circulação desses dizeres: o lançamento do serviço de checagem Estadão Verifica em junho de 2018, quatro meses antes da votação em primeiro turno para eleições presidenciais no Brasil. O ano eleitoral é uma das justificativas trazidas no discurso sobre o serviço para a sua implementação, como se marca na SD3, em: "a fim de combater a desinformação neste ano eleitoral e também depois disso”. Essa aproximação entre as práticas eleitorais e a 
necessidade do estabelecimento de processos de checagem também é marcada explicitamente na notícia que anuncia o início dos trabalhos do blog É isso mesmo?, associado ao jornal O Globo, e que analisaremos posteriormente. Em O Globo, são retomados os casos do referendo para decidir se o Reino Unido sairia ou não da União Europeia, conhecido como Brexit, e das eleições dos Estados Unidos como momentos em que "[...] uma onda de boatos tomou conta da rede" (SILVA, 2017). Esses mesmos momentos são citados por Adorno e Silveira (2019, p. 204), como dois “acontecimentos marcantes" trazidos pela equipe de lexicografia do Dicionário Oxford que corroboraram para que post-truth (pós-verdade) fosse eleita a palavra do ano em 2016. Na rede parafrástica, pós-verdade, fake news, boatos dão sustentação à constituição dos serviços de checagem, que passam a constituir para si mesmos o imaginário de elemento imprescindível no cenário eleitoral.

No conjunto de quatro sequências discursivas que trouxemos, constitui-se uma rede de deslizamentos de sentidos que marca, no fio do discurso, a oposição entre o boato e o fato, conforme apontamos a seguir:

boato pelo WhatsApp $\rightarrow$ textos, áudios, fotos e vídeos suspeitos no WhatsApp $\rightarrow$ notícias falsas $\rightarrow$ rumores $\rightarrow$ desinformação $\rightarrow$ fake news $\rightarrow$ mentiras

Na SD1, que traz o título da notícia de anúncio do serviço de checagem, é especificado o que deve ser enviado pelos leitores para checagem: os "boatos recebidos pelo WhatApp", em forma de "textos, áudios, fotos e vídeos", qualificados como "suspeitos" (SD2). Pelo funcionamento do efeito metafórico, que, segundo Pêcheux (1997 [1969], p. 96), consiste no "fenômeno semântico produzido por uma substituição contextual" no qual ocorre o "deslizamento de sentidos' entre x e y" "boato" é retomado na SD2 por "notícias falsas" e por "rumores dos leitores"; na SD3, por sua vez, a rede de sentidos se assenta em "desinformação" e "fake news", que posteriormente, na SD4, será discursivizada como "mentiras". Na rede de sentidos que se estabelece pelas substituições de boato, no conjunto dessas quatro sequências discursivas, sustenta-se a oposição empregada como slogan do serviço de checagem Estadão Verifica: "checar fatos e desmentir boatos". Na constituição de sentidos para o blog de checagem, fatos se opõem a boatos, que deslizam para notícias falsas, rumores, desinformação, fake news, mentiras; entre os fatos e as mentiras se localizam os serviços de checagem.

Passamos agora à análise de como se constituem os sentidos para o serviço de checagem do jornal O Globo, detendo-nos, também, sobre quatro sequências discursivas recortadas de notícia (SILVA, 2017) que anuncia o início de suas atividades:

\section{SD5: O Globo lança blog de checagem de notícias}

Jornal investe no combate à proliferação de informações falsas

SD6: Jornais investem na checagem de notícias (fact-checking) como forma de filtrar a proliferação de fatos falsos ( $\underline{\text { fake news) }}$

SD7: O jornal O Globo estreou nesta segunda-feira, 27, o blog feito por grupo especializado em checagem de fatos, chamado É isso mesmo? O objetivo é checar discursos e anúncios de autoridades e também boatos disseminados nas redes sociais contra a proliferação de notícias falsas.

SD8: "Queremos ajudar o consumidor a tomar decisões corretas, informando o que é falso ou verdadeiro", afirma o diretor de redação do Globo, Ascânio Seleme.

Nas sequências discursivas recortadas de $O$ Globo, temos em funcionamento, no fio do discurso, efeitos de sentidos de sobreposição entre "notícias", "informações" e "fatos". Pelo funcionamento do efeito metafórico (PÊCHEUX, 1997 [1969]), "checagem de notícias", no título (trazido em negrito), é associada à "proliferação de informações falsas”, na linha fina que o acompanha (na SD5). "Notícias" e "informações", desse modo, podem ser tomadas em uma relação imaginária de equivalência no dizer do jornal ${ }^{3}$. Funcionamento discursivo semelhante observamos na SD6, na qual recortamos a legenda da foto que compõe o texto da matéria em análise. No fio do discurso, temos a equivalência entre "fatos falsos" e "fake news", o que se marca na retomada da expressão em inglês, entre parênteses, como explicação para "fatos falsos". "Informações falsas", na SD5, desliza, assim, para "fatos falsos" e para

${ }^{3}$ Acerca da distinção entre notícia e informação, ver Flores e Neckel (2019). 
"fake news" (na SD6), promovendo o efeito de sentido de que "notícia" e "fato" seriam equivalentes. Esse funcionamento, próprio da ideologia que, conforme afirma Pêcheux (1997a [1975], p. 160), "fornece as evidências [...] que fazem com que uma palavra ou um enunciado 'queiram dizer o que realmente dizem'”, marca o já-dito do jornalismo como um relato imaginariamente isento e objetivo dos fatos. Pois, se é preciso qualificar “informações" e "fatos" como falsos, é justamente porque funciona como uma evidência o jádito de que a notícia, as informações, os fatos, sem adjetivação, seriam aqueles associados a um imaginário de verdade; prática que a checagem de notícias buscaria restituir.

Essa relação de oposição entre "falso" e "verdadeiro" é trazida de forma explícita no dizer atribuído ao diretor de redação do Globo, ao discorrer sobre o propósito do serviço de checagem de notícias então anunciado (na SD8). Ao posicionar o jornal, pela intervenção do serviço de checagem, como sendo imaginariamente capaz de atestar o que é "falso" e o que é "verdadeiro", tal dizer faz ressoar a memória discursiva da prática jornalística como um serviço de utilidade pública, capaz de promover a separação entre esses dois polos; e, desse modo, propício a "ajudar o consumidor a tomar decisões corretas". A esse já-dito do jornalismo como um serviço, soma-se a memória dessa prática como aquela destinada a fiscalizar os poderes em exercício, conforme aponta a SD7, ao especificar na materialidade linguística o que será checado pelo novo serviço: "isscursos e anúncios de autoridades e também boatos disseminados nas redes sociais". O imaginário da prática jornalística como sendo aquela capaz de conferir se "discursos e anúncios de autoridades" são verídicos se sustenta na memória do jornalismo como o quarto poder ${ }^{4}$, responsável por fiscalizar as instâncias de poder em nossa conjuntura sócio-histórica. A essa função, já estabilizada nos já-ditos sobre a imprensa e suas práticas, é acrescida a checagem dos "boatos disseminados nas redes sociais", como marcado na forma adverbial "também".

O boato, conforme teoriza Orlandi (2001a, p. 131), “[... é um fato relevante para se observar essa faixa do dizer que está entre o atestado e o possível. Margem opaca onde o dizer não está estabelecido em sua positividade e nem por isso deixa de existir, de fazer sentidos.". Ao analisar o funcionamento discursivo do boato na história do Brasil, voltando-se a discursos sobre a colonização, Orlandi (2001a) aponta que o boato é uma presença nessa história desde os seus primórdios, dando a ver o modo como disputas de sentidos e relações de força foram configurando a sociedade brasileira. Em seus termos, o boato se constitui como "[...] um fato da vida social pública, traço do funcionamento coletivo da palavra" (ORLANDI, 2001a, p. 132) e, naquele contexto sócio-histórico, também funcionava como uma forma de resistência ao poder da metrópole portuguesa sobre a colônia. Assim, ainda conforme Orlandi: "Conhecer, controlar e fazer circularem os boatos são um meio de estabelecer uma forma de poder" (2001a, p. 132).

Ao colocar-se entre "o fato" e "o boato", a mídia jornalística, agora valendo-se das agências de checagem de notícias, (re)afirma o seu conhecimento sobre "os fatos" (atestado pela via da apuração da verdade), bem como sua possibilidade de controlar a circulação dos boatos; assim, a mídia jornalística (re)afirma para si mesma a imagem de uma instância de poder capaz de estabelecer os limites entre a notícia, de um lado, e os boatos, as notícias falsas e as mentiras, de outro.

Para pensarmos esse funcionamento das agências de checagem de notícias, passamos a um segundo gesto de análise, agora voltado ao modo como os blogs Estadão Verifica e É isso mesmo? estabelecem categorias para o trabalho de checagem que realizam. Iniciamos com a análise de um conjunto de seis imagens, capturadas de um vídeo com duração de um minuto, disponibilizado no blog Estadão Verifica (Quadro 1):

\footnotetext{
${ }^{4}$ Sobre a designação da mídia como o quarto poder, assim afirma Traquina (2005, p. 46): "No novo enquadramento da democracia, com o princípio de 'poder controla poder' (power checks power), a imprensa (os media) seria o 'quarto’ poder em relação aos outros três: o poder executivo, o legislativo e o judicial.”.
} 


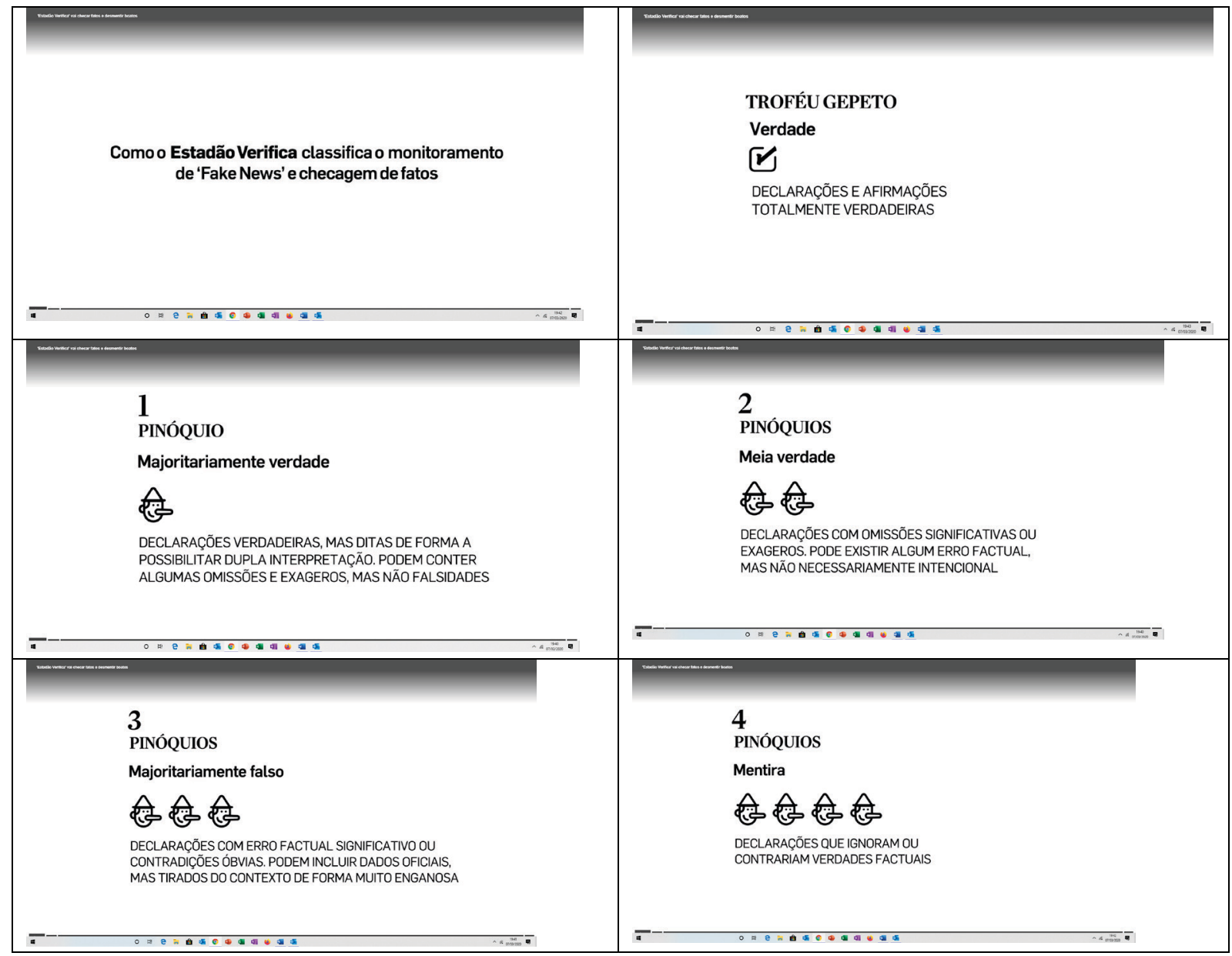

Quadro 1: Print screen do vídeo "Como o Estadão Verifica classifica o monitoramento de 'Fake News' e checagem de fatos"

Fonte: Vídeo Estadão Verifica ([2020?])

No conjunto de seis imagens capturados do vídeo, expostos no Quadro 1, podemos observar que "o monitoramento de "Fake News" e a checagem de fatos", anunciados pelo Estadão Verifica organizam os materiais checados em cinco categorias, valendo-se, para isso, do recurso à história do Pinóquio, personagem de romance italiano do século XIX, adaptado mundialmente para filmes e desenhos animados. A primeira categoria - Troféu Gepeto - em uma alusão ao nome do criador de Pinóquio, é aquela reservada à "verdade", contendo "declarações e afirmações totalmente verdadeiras", conforme o blog. A essa categoria, seguem-se outras quatro, especificadas por diferentes números de Pinóquios, a saber: 1) "majoritariamente verdade"; 2) "meia verdade"; 3) "majoritariamente falso"; 4) "mentira". Na descrição de cada categoria, o processo parafrástico aponta o modo como se diz dos limites entre "o fato" e o "boato", conforme desdobramos no quadro a seguir:

\begin{tabular}{c|c|c}
1 & $\begin{array}{c}\text { Declarações verdadeiras, mas ditas de forma a possibilitar } \\
\text { dupla interpretação. }\end{array}$ & $\begin{array}{c}\text { Podem conter algumas omissões e exageros, mas não } \\
\text { falsidades. }\end{array}$ \\
\hline 2 & Declarações com omissões significativas ou exageros. & $\begin{array}{c}\text { Pode existir algum erro factual, mas não necessariamente } \\
\text { intencional. }\end{array}$ \\
\hline 3 & $\begin{array}{c}\text { Declarações com erro factual significativo ou contradições } \\
\text { óbvias. }\end{array}$ & $\begin{array}{c}\text { Podem incluir dados oficiais, mas tirados do contexto de } \\
\text { forma muito enganosa. }\end{array}$ \\
\hline 4 & Declarações que ignoram ou contrariam verdades factuais. &
\end{tabular}

Quadro 2: Síntese da descrição das categorias Pinóquio em Estadão Verifica

Fonte: elaboração da autora 
Na materialidade linguística das descrições de cada categoria de Pinóquio, mobilizadas pelo Estadão Verifica, temos uma recorrência da conjunção "mas": "mas ditas de forma a possibilitar dupla interpretação"; "mas não falsidades"; "mas não necessariamente intencional"; "mas tirados do contexto de forma muito enganosa", que se somam na tentativa de se estabelecer categorias que deem conta de delimitar a pluralidade de sentidos que um dizer pode comportar. Por oposição ao Troféu Gepeto, descrita como atribuído a "declarações e afirmações totalmente verdadeiras", está a categoria 4 Pinóquios, destinada a classificar "declarações que ignoram ou contrariam verdades factuais"; e entre elas, muitos sentidos se movem: "dupla interpretação”, “omissões", "exageros", "omissões significativas", "erro factual", "erro factual significativo", "contradições óbvias", "dados oficiais tirados do contexto de forma muito enganosa”... É assim que, entre "o fato" e "o boato”, os sentidos se movem, deslizam, e dão a ver a falha na disjunção lógica, característica de um mundo semanticamente estável de que nos fala Pêcheux (2008 [1983]), que somente poderia resultar na classificação de um relato como "verdade" ou "mentira". Efeito discursivo semelhante podemos depreender das categorias mobilizadas pelo blog É isso mesmo?, em seus procedimentos de checagem (Quadro 3):

\begin{tabular}{|c|c|}
\hline DECLARAÇÕES & MONITORAMENTO \\
\hline - VERDADEIRO & \multirow{3}{*}{ - $\quad$ CUMPRIDO } \\
\hline \multicolumn{2}{|l|}{ Verificamos que a informação está correta. } \\
\hline \multicolumn{2}{|l|}{ - $\quad F A L S O$} \\
\hline Informação errada, falsa ou boato. & \\
\hline - $\quad$ NÃO HÁ CONFIRMAÇÃO & \\
\hline \multirow{2}{*}{$\begin{array}{l}\text { Não existem dados ou fontes públicas que possam confirmar ou } \\
\text { rejeitar a informação. }\end{array}$} & Meta ou projeto foi concluído dentro do prazo estabelecido. \\
\hline & - CUMPRIDO PARCIALMENTE \\
\hline$\bullet \quad N \tilde{O} O$ SESUSTENTA & $\begin{array}{l}\text { Meta ou projeto apresenta resultados, mas não atingiu } \\
\text { completamente os objetivos estabelecidos. }\end{array}$ \\
\hline \multirow{2}{*}{$\begin{array}{l}\text { Afirmação entra em contradição com outras prestadas pela } \\
\text { mesma pessoa e/ou instituição. }\end{array}$} & \\
\hline & - $\quad E M A N D A M E N T O$ \\
\hline - VERDADEIRO, MAS... & Meta ou projeto em desenvolvimento dentro do prazo. \\
\hline $\begin{array}{l}\text { Informação confirmada parcialmente porque está desatualizada, } \\
\text { fora de contexto ou faltam dados. }\end{array}$ & \multirow{2}{*}{$\begin{array}{l}\qquad S O ́ \text { NA PROMESSA } \\
\text { A meta ou projeto não saiu do papel desde o anúncio das } \\
\text { autoridades. }\end{array}$} \\
\hline - $\quad$ NÃOE BEM ASSIM & \\
\hline $\begin{array}{l}\text { Informação com interpretação parcial de um dado, fato ou } \\
\text { acontecimento. }\end{array}$ & \\
\hline $\begin{array}{c}\bullet \quad \text { CONTROVERSO } \\
\text { Informações ou dados com versões contraditórias de duas ou } \\
\text { mais fontes. }\end{array}$ & \\
\hline
\end{tabular}

Quadro 3: Categorias de declarações e checagens do blog “É isso mesmo?

Fonte: BLOG É ISSO MESMO? (2021) 
No blog É isso mesmo?, observamos que são separadas para análise as declarações dos monitoramentos. Os monitoramentos dizem respeito ao acompanhamento, pelo blog, de metas ou projetos anunciados previamente em sua situação atual: se cumpridos, cumpridos parcialmente, em andamento ou não cumpridos ("só na promessa"). As declarações, por sua vez, dizem respeito ao serviço de checagem propriamente, tal como aquele analisado previamente no caso do blog Estadão Verifica. São sete as categorias (retratadas no quadro 3 nas mesmas cores de fonte que aparecem no blog) consideradas: 1) "verdadeiro"; 2) "falso"; 3 ) "não há confirmação"; 4) "não se sustenta”; 5) "verdadeiro, mas...”; 6) "não é bem assim”; 7) “controverso". Além das categorias 1 e 2, que se sustentam imaginariamente pela disjunção lógica entre "verdadeiro" ou "falso", sentidos outros se inscrevem, em uma recorrência da negação: "Não há confirmação", "Não se sustenta", "Não é bem assim”, e em formulações que marcam a impossibilidade do sentido unívoco e da completude dos relatos.

Pêcheux (1997a [1978] p. 301) já nos advertia para o fato de a ideologia configurar-se como um ritual, bem como para a inexistência de "um ritual sem falhas", sem "enfraquecimentos e brechas". Na prática discursiva das agências de checagem de notícias associadas à mídia tradicional, a oposição entre "fato" e "boato", imaginariamente buscada via apuração jornalística, que estabelece o limite entre a prática de produção de notícias e a disseminação de boatos e fake news, também é aquela que denuncia, por meio das categorias que estabelece para o enquadramento de cada notícia ou declaração, a possibilidade de ela ser uma coisa e outra; a possibilidade de o sentido não ser único; o funcionamento da contradição nos discursos.

\section{DAS IMPLICAÇÕES PARA O DISCURSO JORNALÍSTICO: CONSIDERAÇÕES FINAIS}

No percurso que aqui traçamos, localizamos as discussões teórico-analíticas que trouxemos na atualidade, ancorando-as na análise de dizeres em curso nos blogs de checagem de notícias Estadão Verifica e É isso mesmo, associados, respectivamente, a dois grandes grupos da mídia tradicional: O Estado de S. Paulo e O Globo. Nos discursos que analisamos, pudemos perceber o modo como o contexto sócio-histórico e circunstâncias enunciativas específicas, dentre elas, o fenômeno de ampla circulação de fake news via redes sociais, sustentam discursivamente o surgimento e a consolidação dessas agências de checagem associadas à prática jornalística no Brasil.

Acerca das fake news e de seu funcionamento discursivo, assim afirma Indursky, em entrevista:

\footnotetext{
À luz da Análise do Discurso, entendo fakenews como um processo de torção discursiva realizado sob o efeito de uma identificação ideológica. A torção se dá no momento em que determinado acontecimento é narrado pela mídia de modo a projetar um efeito de verdade ao que, de fato, é uma falsificação do ocorrido. [...] Se a referida torção discursiva for aceita, ela passa a produzir o desejado efeito de verdade. A prática discursiva da falsificação da notícia adquiriu, no fazer político de nossos dias, uma força muito grande, sinalizando que a versão tem muito mais adesão do que o acontecido. (INDURSKY, 2019 apud MARIANI; DELA-SILVA, 2019, p. 29)
}

Ao apontar para o funcionamento de uma torção discursiva que resulta na produção de fake news, de modo que o efeito de verdade se produza, Indursky sinaliza para a relação entre a mídia e a falsificação de notícias. Ao atuar na construção do acontecimento jornalístico, conforme vimos afirmando (DELA-SILVA, 2015), a mídia também pode atuar nesse processo de torção discursiva que de nos fala Indusrky; o processo que leva à circulação de sentidos, via construção de acontecimentos jornalísticos, também pode levar à circulação de boatos e notícias falsas. Em análises acerca do boato, que datam de quase duas décadas atrás, Orlandi (2001b, p. 144) já fazia advertência semelhante, ao afirmar: "Definido como 'notícia anônima que se expande publicamente sem confirmação', pela própria definição, o boato coloca em foco a ideia de notícia, de anonimato, de publicidade e de incerteza. Atinge em cheio a questão da informação e da autoria”. E, conforme aponta a autora, coloca questões, levando-nos a refletir acerca “[...] dos sentidos na relação entre fato e linguagem: onde estão? Qual seu percurso? São válidos? É possível separar verdadeiro e falso? Qual é o grau de certeza em relação a uma notícia?" (ORLANDI, 2001b, p. 144).

No momento em que Orlandi (2001b) formulava tais reflexões, por volta do ano 2000, o jornalismo digital começava a tomar forma com a criação dos primeiros portais de notícias no Brasil e a chegada à rede eletrônica de práticas discursivo-midiáticas. Naquele 
momento, à circulação de boatos via e-mail, muitas vezes assumidos pela mídia como pauta, seguiam-se investigações que acabavam por sustentar a imagem de credibilidade do discurso jornalístico nessas apurações, sobretudo da imprensa. Nos tempos atuais, as condições de circulação dos discursos são outras, mas as agências de checagem de notícias, em seus dizeres de si e de suas práticas, seguem assumindo esse trabalho de afirmação do jornalismo como associado à isenção, objetividade e transparência. Assim, com a prática das agências de checagem associadas à mídia tradicional, podemos afirmar, retomando Orlandi (2001b, p. 148), que: "Está salva a ideia de informação e com ela a de objetividade da notícia, a de verdade".

Em análise acerca de pós-verdade e fake news na materialidade digital, Adorno e Silveira (2019) questionam acerca da possibilidade de se tomar a checagem realizada pelas agências de fact checking como uma nova forma de gestão de poder. As reflexões que aqui trouxemos nos levam a afirmar que as agências de checagem - aos moldes que têm sido implementadas no Brasil - levam à manutenção da mídia como instância de poder, que segue produzindo sempre um "invisível”, como já afirmava Pêcheux, na epígrafe que trouxemos para este artigo. E, com Orlandi (2001b, p. 148), sabemos que: "Na relação entre o Poder e Vento, as palavras assopradas que falam mais são aquelas que o poder sopra.".

\section{REFERÊNCIAS}

ADORNO, G.; SILVEIRA, J. Pós-verdade e fake news: equívocos do político na materialidade digital. In: GRIGOLETTO, E.; DE NARDI, F.S.; SOBRINHO, H.F.S. (org.). Sujeito, sentido, resistência: entre a arte e o digital. Campinas: Pontes Editores, 2019. p. 201218.

BLOG É ISSO MESMO? Disponível em: https://blogs.oglobo.globo.com/eissomesmo/. Acesso em: 17 ago. 2021.

CALEIRO, M. Checando as agências de fact-checking. Observatório da Imprensa. Edição 1073, 4 fev. 2020. Disponível em: http://www.observatoriodaimprensa.com.br/checagem-de-informacoes/checando-as-agencias-de-fact-checking/. Acesso em: 8 mar. 2020.

DELA-SILVA, S. Da resistência aos discursos da/na mídia: sobre eventos e páginas no Facebook. In: SOUSA, L.M.A. et al. (org.). Resistirmos, a que será que se destina? São Carlos: Pedro \& João Editores, 2018. p. 273-295.

DELA-SILVA, S. (Des)Construindo o acontecimento jornalístico: por uma análise discursiva dos dizeres sobre o sujeito na mídia. In: FLORES, G.B.; NECKEL, N.R.M.; GALLO, S.M.L. (org.). Análise de discurso em rede: cultura e mídia. Campinas-SP: Pontes Editores, 2015. p. 213-232.

DELA-SILVA, S. Das cartas de leitores às redes sociais: o espaço para o sujeito na revista Superinteressante. Estudos Linguísticos, São Paulo, v. 42, n. 3, p. 1214-1228, set./dez. 2013.

IFCN. Poynter Institute. Verified signatories of the ITCN code of principles. Disponível em: https://ifcncodeofprinciples.poynter.org/signatories. Acesso em: 8 mar. 2020.

FLORES, G.B.; NECKEL, N.R.M. Notícia ou informação? Efeito de neutralidade e silenciamentos históricos. In: GRIGOLETTO, E.; DE NARDI, F.S.; SOBRINHO, H.F.S. (org.). Silêncio, memória, resistência: a política e o político no discurso. Campinas: Pontes Editores, 2019. p. 261-274.

GRUPO GLOBO. Princípios editoriais do Grupo Globo. Disponível em: http:/g1.globo.com/principios-editoriais-do-grupoglobo.html\#topo. Acesso em: 6 abr. 2020. 
LUPA. O que é a agência Lupa? UOL. 15 out. 2015 [com atualização em 23 jan. 2020]. Disponível em: https://piaui.folha.uol.com.br/lupa/2015/10/15/como-selecionamos-as-frases-que-serao-checadas/. Acesso em: 8 mar. 2020.

MARIANI, B. O PCB e a imprensa: os comunistas no imaginário dos jornais (1922-1989). Rio de Janeiro: Revan; Campinas, SP: Editora da Unicamp, 1998.

MARIANI, B.; DELA-SILVA, S. Discurso político: processos de significação em tempos de fake news - Uma entrevista com Freda Indursky. Caderno de Letras UFF, Niterói, v. 30, n. 59, p. 13-31, jul./dez. 2019.

MARTINS, E. Manual de redação e estilo de O Estado de S. Paulo. 3 ed. São Paulo: o Estado de S. Paulo, 1997.

MONNERAT, A. Estadão Verifica recebe certificação de entidade internacional de fact checking. Estadão Verifica. 16 jan. 2019. Disponível em: https://politica.estadao.com.br/blogs/estadao-verifica/estadao-verifica-recebe-certificacao-de-entidadeinternacional-de-fact-checking/. Acesso em: 7 mar. 2020.

MONNERAT, A. Recebeu algum boato pelo WhatsApp? Envie para o Estadão Verifica. Estadão. 13 jun. 2018. Disponível em: https://politica.estadao.com.br/blogs/estadao-verifica/recebeu-algum-boato-pelo-whatsapp-envie-para-o-estadao-verifica/. Acesso em: 7 mar. 2020.

MORETZON, S. Jornalismo em tempo real: o fetiche da velocidade. Rio de Janeiro: Revan: 2002.

ORLANDI, E. Análise de discurso: princípios e procedimentos. 3. ed. Campinas: Pontes Editores, 2001.

ORLANDI, E. Boatos e silêncios: os trajetos dos sentidos, os percursos do dizer. In: ORLANDI, E. Discurso e texto: formulação e circulação dos sentidos. Campinas: Pontes, 2001a. p. 127-140.

ORLANDI, E. Palavras ao vento ou o poder e o vento. In: ORLANDI, E. Discurso e texto: formulação e circulação dos sentidos. Campinas: Pontes, 2001b. p. 141-148.

PÊCHEUX, M. Análise Automática do Discurso (AAD-69). In: GADET, F.; HAK, T. (org.). Por uma análise automática do discurso: uma introdução à obra de Michel Pêcheux. 3. ed. Campinas, SP: Editora da Unicamp, 1997 [1969]. p. 61-162.

PÊCHEUX, M. [1975]. Semântica e Discurso: uma crítica à afirmação do óbvio. 3 ed. Campinas: Editora da Unicamp, 1997a. [1975].

PÊCHEUX, M. Delimitações, inversões, deslocamentos. Caderno Estudos Linguísticos, Campinas, v. 19, p. 7-24, jul./dez., 1990 [1982].

PÊCHEUX, M. O discurso: estrutura ou acontecimento. 5 ed. Campinas, SP: Pontes Editores, 2008 [1983].

PENA, F. Teoria do jornalismo. 3. ed. São Paulo: Editora Contexto, 2015.

SILVA, S.D. O Globo lança blog de checagem de notícias. Meio \& Mensagem. 27 mar. 2017. Disponível em: https://www.meioemensagem.com.br/home/midia/2017/03/27/o-globo-lanca-blog-de-checagem-de-noticias.html. Acesso em: 7 mar. 2020.

TRAQUINA, N. Teorias do jornalismo: porque as notícias são como são. V. 1. Florianópolis: Insular, 2005. 
VÍDEO Estadão Verifica.[2020?]. Disponível em: https://politica.estadao.com.br/blogs/estadao-verifica/estadao-verifica-recebecertificacao-de-entidade-internacional-de-fact-checking/. Acesso em: 15 mar. 2021.

() (1) $\circledast$

Recebido em 07/04/2020. Aceito em 25/05/2020. 